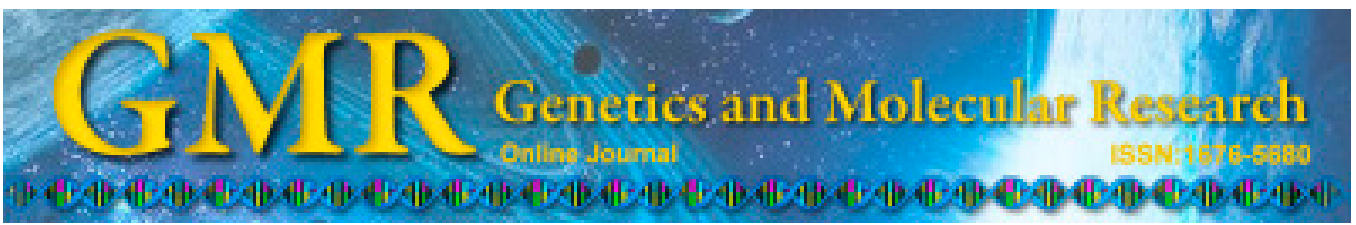

\title{
Impact of enteral nutrition on postoperative immune function and nutritional status
}

\author{
F. Wang ${ }^{1}$, M.X. Hou ${ }^{1}$, X.L. Wu ${ }^{1}$, L.D. Bao ${ }^{2}$ and P.D. Dong ${ }^{1}$ \\ ${ }^{1}$ Department of General Surgery, \\ Affiliated Hospital of Inner Mongolia Medical University, Hohhot, China \\ ${ }^{2}$ Department of Pharmacy, \\ Affiliated Hospital of Inner Mongolia Medical University, Hohhot, China \\ Corresponding authors: F. Wang / P.D. Dong \\ E-mail: wangfeng201210@163.com / dongpeide201210@163.com
}

Genet. Mol. Res. 14 (2): 6065-6072 (2015)

Received May 21, 2014

Accepted October 29, 2014

Published June 8, 2015

DOI http://dx.doi.org/10.4238/2015.June.8.4

\begin{abstract}
We studied the effects of enteral nutrition (EN) support initiated 1 week before surgery on postoperative nutritional status, immune function, and inflammatory response in gastric cancer patients. A total of 200 gastric cancer patients were randomly divided into two groups: EN starting 1 week before surgery (study group) and EN starting early after surgery (control group). The two groups received EN support, following different therapeutic schedules, until the 9th day after operation. In the patients, body weight, skinfold thickness, upper-arm circumference, white blood cell count, albumin, prealbumin, C-reactive protein, peripheral immunoglobulins ( $\operatorname{IgA}, \operatorname{IgG}$, and IgM), T lymphocyte subsets, interleukin-6, and tumor necrosis factor- $\alpha$ were measured 10 days before and after surgery and on the first day after surgery. There was no statistically significant difference in the results of recovery time of passage of gas by anus, abdominal distension, stomachache, blood glucose, hepatic and renal functions, and electrolytes between the two groups of patients $(P>0.05)$. Adverse reactions occurred to both groups at 1 and 2 days after operation. Such conditions was improved after the intravenous drip rate was adjusted.
\end{abstract}


The albumin and prealbumin levels of the patients in both groups decreased at 1 day after operation $(\mathrm{P}<0.05)$. The levels rose when the research was finished $(\mathrm{P}<0.05)$. The prealbumin level of the study group was higher than that of the control group at 10 days after operation $(\mathrm{P}<0.05)$. The IgG level of the study group was higher than that of the control group at 10 days after operation $(\mathrm{P}<0.05)$. The two groups of inflammatory reaction indicators of the study group were lower than those of the control group at 10 days after operation $(\mathrm{P}<$ $0.05)$. This study indicates that appropriate preoperative EN support for gastric cancer patients can improve their postoperative nutritional status and immune function, can reduce inflammatory response, and is more conducive to the recovery of patients.

Key words: Preoperative; Enteral nutrition; Gastric cancer; Immune function

\section{INTRODUCTION}

Gastric cancer patients show relatively severe malnutrition, as a result of many factors, including surgical trauma, perioperative diet control, and low calorie intake, as well as from factors related to gastric cancer itself (Sultan et al., 2012). It has been shown previously in studies on enteral nutrition (EN) in the surgical treatment of diseases that early EN plays an important role in postoperative recovery. Specifically, preoperative intestinal preparation has gained increasing attention (Fernstrom and Courcoulas, 2008). EN has been confirmed to be important in preoperative bowel preparation (Aydin et al., 2008). Although a consensus has been reached that preoperative and postoperative EN plays a role in improving the nutritional status of gastric cancer patients, its effects on immune function are controversial. It has been shown that EN support early after surgery can improve postoperative immune function in gastric cancer patients (Wang and $\mathrm{Li}, 2011$; Gu et al., 2012). However, little is known about the effects of EN support, starting from preoperative bowel preparation, on indicators related to postoperative nutritional status and immune function in gastric cancer patients. Thus, the aim of this study was to observe the effects of different nutritional formulations for EN support before and after surgery on nutritional status, immune function, and inflammatory response indicators, to study the effects of appropriate preoperative EN on postoperative nutritional status and immune function of gastric cancer patients.

\section{MATERIAL AND METHODS}

\section{Study design}

A total of 200 gastric cancer patients, including 130 males and 70 females (aged 38-72 years) who were treated with radical surgery at the Affiliated Hospital of Inner Mongolia Medical University between June 2010 and June 2012, were included in the study. The patients were divided into the study group (preoperative EN group, $\mathrm{N}=100$ ) and the control group (early postoperative EN group, $\mathrm{N}=100$ ). The SAS9.13 software generated random numbers and performed random allocation at a ratio of 1:1 for the study and control groups. The alloca- 
tion sequences generated randomly were placed in sealed opaque envelopes that were coded by sequence. After confirming the eligibility of patients, researchers matched tumor staging of the patients within the same batch, opened the envelopes in sequence, and allocated the patients into a group. No patient had vital organ dysfunction or metabolic or endocrine diseases during the preoperative examination. The two groups did not differ significantly in tumor staging $(\mathrm{P}=0.65)$, surgical method $(\mathrm{P}=0.55)$, or duration of operation $(\mathrm{P}=0.60)$.

\section{Nutrition support methods}

\section{Study group}

Patients in the study group were given $1000 \mathrm{kcal} /$ day Nutrison, which is an intact protein-based full-nutritional enteral powder (German Nutricia Export B.V.) that contains dietary fiber and an energy density of $1 \mathrm{kcal} / \mathrm{mL}$. For 1 week before surgery, Nutrison was taken orally. Twelve hours after surgery, $250 \mathrm{~mL}$ isotonic sodium chloride solution was given. On the first day after surgery, $250 \mathrm{~mL}$ isotonic sodium chloride solution and $500 \mathrm{~mL}$ Peptison, which is a short-peptide-based element diet [Nutricia (Wuxi) Company], was infused through a nasointestinal tube with EN pump, with infusion of the Peptison initiated $24 \mathrm{~h}$ after surgery. On the second day after surgery, $1000 \mathrm{~mL}$ Peptison was infused; on the third day after surgery, $500 \mathrm{~mL}$ Peptison plus $500 \mathrm{~mL}$ Nutrison preparation solution was infused with the initiation of infusion of the latter starting $72 \mathrm{~h}$ after the operation. From the third to the ninth days after surgery, $1000 \mathrm{~mL}$ Peptison was infused continuously through nasointestinal tube with EN.

\section{Control group}

On the first day after surgery, patients in the control group were infused with $250 \mathrm{~mL}$ isotonic sodium chloride solution. On the second day after surgery, $250 \mathrm{~mL}$ isotonic sodium chloride solution plus $500 \mathrm{~mL}$ Nutrison was infused continuously through a nasointestinal tube with EN pump, with initiation of the infusion of the latter starting $48 \mathrm{~h}$ after surgery. From the third to the ninth days after surgery, $1000 \mathrm{~mL}$ Nutrison was infused continuously.

\section{Monitoring contents and methods}

\section{Clinical observations}

Patients were observed daily for nausea, vomiting, abdominal distension, abdominal pain, and diarrhea, as well as for intestinal obstruction and intestinal fistula or other complications, and the recovery time for anus exhaust was recorded. Ten days before and after surgery, we measured the body mass, skinfold thickness, and upper-arm circumference of all patients.

\section{Laboratory measurements}

Ten days before and after surgery and one day after surgery, blood white blood cell count, albumin, prealbumin, and C-reactive protein were measured. Enzyme-linked immunosorbent assays were performed to measure peripheral blood immunoglobulins (IgG, IgM, and IgA), peripheral blood cytokine interleukin-6 (IL-6), and tumor necrosis factor- $\alpha$ (TNF- $\alpha$ ). T 
lymphocyte subsets $(\mathrm{CD} 4+\mathrm{T}$ cells, $\mathrm{CD} 8+\mathrm{T}$ cells, and $\mathrm{CD} 4+/ \mathrm{CD} 8+\mathrm{T}$ cells) were measured by flow cytometry.

\section{Statistical analysis}

SPSS18. 0 was used to perform statistical analysis. Numerical variables are reported as means \pm standard deviation and were analyzed using repeated measurement analysis of variance. Two-sided tests were performed for all statistical tests. F-tests were performed to compare count data and $t$-tests were performed to compare measurement data. P values of less than 0.05 were considered to be statistically significant.

\section{RESULTS}

\section{Comparison of clinical changes between groups}

Patients in both groups completed treatment on schedule, without the incidence of acute intestinal obstruction, intestinal fistula, or other complications. The groups differed significantly in anal exhaust recovery time $(\mathrm{P}=0.19)$. While the incidence of abdominal distension and pain was $5.19 \%$ in the study group, it was $9.55 \%$ in the control group; however, this difference was not statistically significant $(\mathrm{P}=0.33)$. There were no significant differences in blood sugar, liver and kidney functions, or electrolyte detection between the two groups (Table 1). The adverse reactions in both groups occurred on the first and second days after the operation and improved following the adjustment of the infusion rate (Table 1).

\begin{tabular}{|c|c|c|c|c|c|c|c|}
\hline & \multicolumn{2}{|c|}{ Control group } & \multicolumn{2}{|c|}{ Study group } & \multirow[t]{2}{*}{$t$-test } & \multirow[t]{2}{*}{ d.f. } & \multirow[t]{2}{*}{$P$ value } \\
\hline & Mean & SD & Mean & SD & & & \\
\hline Blood magnesium (mM) & 0.903 & 0.134 & 0.864 & 0.182 & 1.72 & 182 & 0.08 \\
\hline Serum creatinine $(\mu \mathrm{M})$ & 47.375 & 18.997 & 51.367 & 22.148 & 1.37 & 198 & 0.17 \\
\hline Glutamic oxaloacetic transaminase (U/L) & 17.808 & 5.033 & 16.794 & 5.686 & 1.34 & 198 & 0.18 \\
\hline Recovery time of anus exhaust (days) & 1.24 & 0.336 & 1.299 & 0.294 & 1.32 & 198 & 0.19 \\
\hline Glutamic pyruvic transaminase (U/L) & 15.252 & 5.749 & 15.866 & 5.879 & 0.75 & 198 & 0.46 \\
\hline Fasting blood sugar $(\mathrm{mM})$ & 5.571 & 1.054 & 5.65 & 1.049 & 0.53 & 198 & 0.60 \\
\hline Blood urea nitrogen $(\mu \mathrm{M})$ & 1.296 & 0.433 & 1.312 & 0.452 & 0.26 & 198 & 0.80 \\
\hline Blood potassium (mM) & 4.371 & 0.684 & 4.39 & 0.673 & 0.19 & 198 & 0.85 \\
\hline Blood sodium $(\mathrm{mM})$ & 138.602 & 2.663 & 138.611 & 2.328 & 0.03 & 198 & 0.97 \\
\hline Blood phosphate (mM) & 1.166 & 0.238 & 1.167 & 0.238 & 0.02 & 198 & 0.99 \\
\hline Blood calcium (mM) & 2.188 & 0.242 & 2.188 & 0.259 & 0.02 & 198 & 0.99 \\
\hline
\end{tabular}

d.f., degrees of freedom; SD, standard deviation.

\section{Comparison of nutrition indicators between groups}

There were no significant differences in body weight, skinfold thickness, or upper-arm circumference between the study and control groups 10 days before and after surgery (Table 2). The albumin and prealbumin levels of the two groups decreased on the first day after the operation $(\mathrm{P}<0.05$; Table 2) and increased at the end of the study $(\mathrm{P}<0.05$; Table 2$)$. The prealbumin levels in the study group were higher than the control group $(\mathrm{P}<0.05$; Table 2$)$. 
Table 2. Differences in nutritional indicators between control and study groups.

\begin{tabular}{|c|c|c|c|c|c|c|}
\hline & \multicolumn{2}{|c|}{ Control group } & \multicolumn{2}{|c|}{ Study group } & \multirow[t]{2}{*}{ F-test } & \multirow[t]{2}{*}{$\mathrm{P}$ value } \\
\hline & Mean & SD & Mean & SD & & \\
\hline \multicolumn{7}{|l|}{ Before } \\
\hline ALB & 39.658 & 3.063 & 38.533 & 7.941 & 19.39 & 0.00 \\
\hline $\mathrm{PA}(\mathrm{mg} / \mathrm{L})$ & 213.893 & 32.553 & 235.218 & 43.433 & 19.39 & 0.00 \\
\hline Skinfold thickness (mm) & 6.467 & 0.959 & 6.786 & 0.774 & & \\
\hline Upper-arm circumference (mm) & 23.133 & 2.138 & 22.979 & 2.518 & & \\
\hline Weight $(\mathrm{kg})$ & 45.453 & 3.948 & 45.806 & 3.852 & & \\
\hline \multicolumn{7}{|l|}{ Day 1} \\
\hline ALB & 30.303 & 2.539 & 32.521 & 7.423 & 19.40 & 0.00 \\
\hline $\mathrm{PA}(\mathrm{mg} / \mathrm{L})$ & 183.692 & 38.514 & 186.31 & 16.985 & 20.00 & 0.01 \\
\hline Upper-arm circumference (mm) & 23.428 & 2.04 & 22.556 & 2.427 & & \\
\hline Skinfold thickness $(\mathrm{mm})$ & 6.63 & 0.763 & 6.761 & 0.807 & & \\
\hline \multicolumn{7}{|l|}{ Day 10} \\
\hline ALB & 35.194 & 4.879 & 32.454 & 3.223 & 20.12 & 0.01 \\
\hline $\mathrm{PA}(\mathrm{mg} / \mathrm{L})$ & 193.196 & 20.264 & 248.513 & 41.462 & 20.11 & 0.01 \\
\hline Upper-arm circumference (mm) & 22.823 & 2.387 & 22.798 & 2.183 & 0.08 & \\
\hline Skinfold thickness $(\mathrm{mm})$ & 6.477 & 1.037 & 6.527 & 0.859 & 0.369 & \\
\hline Weight $(\mathrm{kg})$ & 45.706 & 4.074 & 45.049 & 3.846 & 1.172 & \\
\hline
\end{tabular}

Before, 10 days before surgery; Day 1, 1 day after surgery; Day 10, 10 days after surgery; SD, standard deviation; ALB, albumin; PA, prealbumin.

\section{Comparison of changes in immune function indicators between groups}

The immune function indicators of both groups decreased on the first day after the operation $(\mathrm{P}<0.05$; Table 3$)$ and increased by the end of the study $(\mathrm{P}<0.05$; Table 3$)$. The IgG levels in the study group were higher than the control group $(\mathrm{P}<0.05$; Table 3$)$.

Table 3. Differences in immunologic indicators between control and study groups.

\begin{tabular}{|c|c|c|c|c|c|c|}
\hline & \multicolumn{2}{|c|}{ Control group } & \multicolumn{2}{|c|}{ Study group } & \multirow[t]{2}{*}{ F-test } & \multirow[t]{2}{*}{$P$ value } \\
\hline & Mean & SD & Mean & SD & & \\
\hline \multicolumn{7}{|l|}{ Before } \\
\hline $\mathrm{CD} 4+\mathrm{T}$ cell/CD8+ $\mathrm{T}$ cell ratio & 1.746 & 0.615 & 1.796 & 1.008 & 13.99 & 0.03 \\
\hline CD4+ T cell $(\%)$ & 47.713 & 9.082 & 38.172 & 5.902 & 12.07 & 0.03 \\
\hline CD8+ T cell $(\%)$ & 29.383 & 7.546 & 25.347 & 9.127 & 16.12 & 0.02 \\
\hline $\operatorname{IgA}(\mathrm{g} / \mathrm{L})$ & 3.252 & 1.091 & 2.499 & 0.888 & 25.51 & 0.01 \\
\hline $\operatorname{IgG}(\mathrm{g} / \mathrm{L})$ & 12.773 & 3.429 & 11.459 & 1.535 & 15.53 & 0.02 \\
\hline \multicolumn{7}{|l|}{ Day 1} \\
\hline $\mathrm{CD} 4+\mathrm{T}$ cell/CD8+ $\mathrm{T}$ cell ratio & 1.568 & 0.321 & 2.335 & 1.415 & 12.55 & 0.03 \\
\hline CD4+ T cell $(\%)$ & 29.151 & 4.746 & 31.446 & 8.924 & 16.11 & 0.02 \\
\hline CD8+ T cell $(\%)$ & 18.949 & 2.829 & 15.906 & 5.117 & 12.45 & 0.03 \\
\hline $\operatorname{Ig} \mathrm{A}(\mathrm{g} / \mathrm{L})$ & 2.403 & 1.011 & 2.245 & 0.883 & 25.50 & 0.01 \\
\hline $\operatorname{IgG}(\mathrm{g} / \mathrm{L})$ & 9.233 & 2.509 & 10.213 & 1.831 & 10.19 & 0.03 \\
\hline \multicolumn{7}{|l|}{ Day 10} \\
\hline $\mathrm{CD} 4+\mathrm{T}$ cell/CD8+ T cell ratio & 2.148 & 0.704 & 2.987 & 4.976 & 12.90 & 0.03 \\
\hline CD4+ T cell $(\%)$ & 32.399 & 4.161 & 46.08 & 2.339 & 12.08 & 0.02 \\
\hline CD8+ T cell $(\%)$ & 16.163 & 3.874 & 19.781 & 10.095 & 17.01 & 0.02 \\
\hline $\operatorname{IgA}(\mathrm{g} / \mathrm{L})$ & 4.308 & 1.323 & 3.026 & 1.228 & 15.01 & 0.03 \\
\hline $\operatorname{IgG}(\mathrm{g} / \mathrm{L})$ & 10.285 & 1.713 & 12.818 & 2.541 & 15.54 & 0.02 \\
\hline
\end{tabular}

Before, 10 days before surgery; Day 1, 1 day after surgery; Day 10, 10 days after surgery; SD, standard deviation; IgA, immunoglobulin A; IgG, immunoglobulin G. 


\section{Comparison of changes in inflammatory reaction indicators between groups}

The inflammatory reaction indicators and cytokine levels in both groups increased in the first day after the operation ( $\mathrm{P}<0.05$; Table 4$)$, and decreased by the end of the study. The IL-6 levels in the study group were lower than in the control group on the tenth day after the operation ( $\mathrm{P}<0.05$; Table 4$)$.

\begin{tabular}{|c|c|c|c|c|c|c|}
\hline & \multicolumn{2}{|c|}{ Control group } & \multicolumn{2}{|c|}{ Study group } & \multirow[t]{2}{*}{ F-test } & \multirow[t]{2}{*}{$\mathrm{P}$ value } \\
\hline & Mean & SD & Mean & SD & & \\
\hline \multicolumn{7}{|l|}{ Before } \\
\hline $\mathrm{CRP}(\mathrm{mg} / \mathrm{L})$ & 1.76 & 0.305 & 1.488 & 0.287 & 15.50 & 0.02 \\
\hline IL-6 (ng/L) & 341.887 & 85.34 & 333.682 & 78.15 & 25.51 & 0.01 \\
\hline TNF- $\alpha(n g / L)$ & 92.993 & 18.428 & 89.106 & 24.522 & 13.34 & 0.03 \\
\hline $\mathrm{WBC}\left(\times 10^{9} / \mathrm{L}\right)$ & 5.35 & 1.137 & 4.872 & 1.097 & 16.10 & 0.04 \\
\hline \multicolumn{7}{|l|}{ Day 1} \\
\hline $\mathrm{CRP}(\mathrm{mg} / \mathrm{L})$ & 1.592 & 0.286 & 1.354 & 0.274 & 23.97 & 0.01 \\
\hline $\mathrm{IL}-6(\mathrm{ng} / \mathrm{L})$ & 314.157 & 76.494 & 541.548 & 116.33 & & \\
\hline TNF- $\alpha(n g / L)$ & 127.711 & 30.212 & 127.612 & 32.367 & 19.39 & 0.00 \\
\hline $\mathrm{WBC}\left(\times 10^{9} / \mathrm{L}\right)$ & 12.024 & 1.416 & 11.381 & 1.5 & 23.71 & 0.01 \\
\hline \multicolumn{7}{|l|}{ Day 10} \\
\hline $\mathrm{CRP}(\mathrm{mg} / \mathrm{L})$ & 2.133 & 0.299 & 1.689 & 0.303 & 12.07 & 0.03 \\
\hline IL-6 (ng/L) & 407.532 & 95.72 & 483.661 & 79.156 & 15.53 & 0.02 \\
\hline TNF- $\alpha(n g / L)$ & 109.493 & 23.779 & 119.786 & 22.632 & 15.72 & 0.01 \\
\hline $\mathrm{WBC}\left(\times 10^{9} / \mathrm{L}\right)$ & 6.875 & 1.446 & 7.485 & 1.756 & 12.55 & 0.03 \\
\hline
\end{tabular}

Before, 10 days before surgery; Day 1, 1 day after surgery; Day 10, 10 days after surgery; SD, standard deviation; CRP, C-reactive protein; IL-6, interleukin-6; TNF- $\alpha$, tumor necrosis factor $\alpha$; WBC, white blood cells.

\section{DISCUSSION}

Cancer patients, especially those with advanced cancer, often have malnutrition and immune dysfunction. Radical surgery of gastric cancer patients can improve patient catabolism; however, the body is in an immunosuppressive state (Yamagishi, 2006). Surgical stress can cause a systemic inflammatory response that may reduce patient's quality of life, and affect prognosis (Bernabe-Garcia et al., 2011; Aminsharifi et al., 2012). Thus, reasonable and effective nutritional support can positively affect malnourished cancer patients.

It has been shown that small intestine functions begin to resume between 6 and $12 \mathrm{~h}$ after surgery (Somri et al., 2012), indicating that EN support could be started at that time. When the intestine works, enteral nutrition support can be given (Rottiers et al., 2009). The application of EN rather than parenteral nutrition in the postoperative stages has been adopted extensively in clinical practice (Jimenez Jimenez et al., 2011; Sanchez Alvarez et al., 2011; Yi et al., 2012). It has been shown previously that early postoperative nutritional support can reduce surgical trauma-related high metabolism, maintain the functions of the intestinal mucosal barrier, and decrease the incidence of intestinal-borne infections, improving recovery of patients (Willis et al., 2008; Del Pilar Velazquez et al., 2010; Moss et al., 2012; Ong and Fock, 2012).

The available products for enteral nutritional support belong to three categories: amino acid or short-peptide type (element type), intact-protein type (non-element type), and component type. The short-peptide type (element type) has protein hydrolyzate as its nitrogen source and can be absorbed in a short digestive process, which is useful for patients in the early 
stages after surgery (Bonekamp et al., 2010; Tannu et al., 2010; Crowther et al., 2012). In this study, gastric cancer patients received EN support with different nutritional preparations during different perioperative periods, which were chosen depending on functional conditions of the digestive tract (Ichimaru et al., 2012). To improve malnutrition, patients were given 160 $\mathrm{g} /$ day Nutrison orally before surgery for nutritional intervention as early as possible; the predigestive preparation Peptison (short-peptide type) was given in the early stages following the operation to reduce the burden and adverse reactions in the digestive tract and to promote absorption and utilization of various nutrients (Egusa and Otani, 2009). The adverse reactions in the postoperative digestive system that had not been fully restored were avoided as much as possible; the incidence rate of adverse reactions in the study group was $6.77 \%$ and $14-32 \%$ in the control group $(\mathrm{P}<0.05)$. Nutrison was gradually introduced as the dietary fibers it contains play a key role in promoting intestinal recovery (Feltrin et al., 2009). On the first day after surgery, albumin and prealbumin levels in the two groups decreased. On the tenth day after surgery, the prealbumin levels in the study group were higher than the control group. Patients in both groups experienced reduction in immune function on the first day after the operation, which increased at the end of the study; IgG levels in the study group were higher than the control group on the tenth day after surgery. In both groups, cytokine levels increased on the first day after surgery and fell at the end of the study; IL-6 levels in the study group were lower than the control group on the tenth day after surgery. Through the comparison of these indicators, we showed that perioperative partial EN support not only improves postoperative nutritional status (Kaidar-Person and Rosenthal, 2008) and immune function in patients with gastric cancer but also alleviates the inflammatory response after surgical trauma (Salgado Jr. et al., 2010).

Together, the study results indicate that preoperative EN support is conducive for the improvement of gastrointestinal absorption of nutrients in gastric cancer patients. In addition, preoperative EN support improves nutritional status and immune function, alleviates inflammatory reactions caused by postoperative trauma, speeds up the recovery of patients, and enhances the effects of clinical treatment. Future studies are required to optimize EN support to avoid the development of adverse reactions, as well as to identify the specific indications and considerations for its use in many diseases.

\section{REFERENCES}

Aminsharifi A, Salehipoor M and Arasteh H (2012). Systemic immunologic and inflammatory response after laparoscopic versus open nephrectomy: a prospective cohort trial. J. Endourol. 26: 1231-1236.

Aydin U, Yazici P, Yuksekkaya H, Arikan C, et al. (2008). Timing of Roux-en-Y limb reconstruction for pediatric live donor liver transplantation. Transplantation 85: 1431-1435.

Bernabe-Garcia M, Lopez-Alarcon M, Blanco-Favela F, Mancilla-Ramirez J, et al. (2011). Beneficial effects of the n-3 long-chain polyunsaturated fatty acids in surgical patients: updating the evidence. Prostaglandins Leukot. Essent. Fatty Acids 85: 261-266.

Bonekamp NA, Vormund K, Jacob R and Schrader M (2010). Dynamin-like protein 1 at the Golgi complex: a novel component of the sorting/targeting machinery en route to the plasma membrane. Exp. Cell Res. 316: 3454-3467.

Crowther GJ, Quadri SA, Shannon-Alferes BJ, Van Voorhis WC, et al. (2012). A mechanism-based whole-cell screening assay to identify inhibitors of protein export in Escherichia coli by the Sec pathway. J. Biomol. Screen. 17: 535-541.

Del Pilar Velazquez M, Romero Nava LE, Lopez de Avalos DR, Quiroz Garza G, et al. (2010). Clinical practice guidelines. Recurrent infection of the urinary tract in women. Colegio Mexicano de Especialistas en Ginecologia y Obstetricia. Ginecol. Obstet. Mex. 78: S437-459.

Egusa S and Otani H (2009). Soybean protein fraction digested with neutral protease preparation, "Peptidase R", produced by Rhizopus oryzae, stimulates innate cellular immune system in mouse. Int. Immunopharmacol. 9: 931-936. 
Feltrin C, Batista de Morais M, de Cassia Freitas K, Beninga de Morais T, et al. (2009). Effect of soluble fiber pectin on growth and intestinal iron absorption in rats during recovery from iron deficiency anemia. Biol. Trace Elem. Res. 129: 221-228.

Fernstrom MH and Courcoulas AP (2008). Bariatric surgery for the severely obese adolescent. Aesthet. Surg. J. 28: 331-334.

Gu RM, Wen X, Wei D, Ming XZ, et al. (2012). Effect of intraoperative intraperitoneal chemotherapy and postoperative nutritional support on intestinal permeability and cellular immune function in patients with advanced gastric cancer. Zhonghua Wei Chang Wai Ke Za Zhi 15: 468-472.

Ichimaru S, Amagai T, Wakita M and Shiro Y (2012). Which is more effective to prevent enteral nutrition-related complications, high- or medium-viscosity thickened enteral formula in patients with percutaneous endoscopic gastrostomy?: a single-center retrospective chart review. Nutr. Clin. Pract. 27: 545-552.

Jimenez Jimenez FJ, Cervera Montes M, Blesa Malpica AL and Spanish Society of Intensive Care Medicine and Coronary Units - Spanish Society of Parenteral and Enteral Nutrition (SEMICYUC-SENPE) (2011). Guidelines for specialized nutritional and metabolic support in the critically-ill patient. Update. Consensus of the Spanish Society of Intensive Care Medicine and Coronary Units - Spanish Society of Parenteral and Enteral Nutrition (SEMICYUC-SENPE): cardiac patient. Med. Intensiva 35: 81-85.

Kaidar-Person O and Rosenthal RJ (2008). Re: Preoperative nutritional status of patients undergoing Roux-en-Y gastric bypass for morbid obesity. J. Gastrointest. Surg. 12: 397.

Moss A, Bourke MJ, Metz AJ, McLeod D, et al. (2012). Beyond the snare: technically accessible large en bloc colonic resection in the West: an animal study. Dig. Endosc. 24: 21-29.

Ong JP and Fock KM (2012). Nutritional support in acute pancreatitis. J. Dig. Dis. 13: 445-452.

Rottiers P, De Smedt T and Steidler L (2009). Modulation of gut-associated lymphoid tissue functions with genetically modified Lactococcus lactis. Int. Rev. Immunol. 28: 465-486.

Salgado W Jr, Cunha Fde Q, dos Santos JS, Nonino-Borges CB, et al. (2010). Routine abdominal drains after Roux-en-Y gastric bypass: a prospective evaluation of the inflammatory response. Surg. Obes. Relat. Dis. 6: 648-652.

Sanchez Alvarez C, Zabarte Martinez de Aguirre M, Bordeje Laguna L and Spanish Society of Intensive Care Medicine and Coronary Units - Spanish Society of Parenteral and Enteral Nutrition (SEMICYUC-SENPE) (2011). Guidelines for specialized nutritional and metabolic support in the critically-ill patient. Update. Consensus of the Spanish Society of Intensive Care Medicine and Coronary Units - Spanish Society of Parenteral and Enteral Nutrition (SEMICYUCSENPE): gastrointestinal surgery. Med. Intensiva 35: 42-47.

Somri M, Matter I, Parisinos CA, Shaoul R, et al. (2012). The effect of combined spinal-epidural anesthesia versus general anesthesia on the recovery time of intestinal function in young infants undergoing intestinal surgery: a randomized, prospective, controlled trial. J. Clin. Anesth. 24: 439-445.

Sultan J, Griffin SM, Di Franco F, Kirby JA, et al. (2012). Randomized clinical trial of omega-3 fatty acid-supplemented enteral nutrition versus standard enteral nutrition in patients undergoing oesophagogastric cancer surgery. $B r . J$. Surg. 99: 346-355.

Tannu SA, Renzetti LM, Tare N, Ventre JD, et al. (2010). Dual bronchodilatory and pulmonary anti-inflammatory activity of RO5024118, a novel agonist at vasoactive intestinal peptide VPAC2 receptors. Br. J. Pharmacol. 161: 1329-1342.

Wang HX and Li JP (2011). Effects of modified bazhen decoction in assistant with enteral nutrition on the growth hormone, the nutritional state, and the immune function in patients with gastric cancer after operation. Zhongguo Zhong Xi Yi Jie He Za Zhi 31: 1317-1321.

Willis MS, Harris LE and Hergenrader PJ (2008). On traditional dental extraction: case reports from Dinka and Nuer en route to restoration. Br. Dent. J. 204: 121-124.

Yamagishi F (2006). The clinical features for tuberculosis in compromised hosts. Kekkaku 81: 631-638.

Yi F, Ge L, Zhao J, Lei Y, et al. (2012). Meta-analysis: total parenteral nutrition versus total enteral nutrition in predicted severe acute pancreatitis. Intern. Med. 51: 523-530. 